Josip Arnerić

University of Zagreb

Faculty of Economics $\mathcal{E}$ Business

10000 Zagreb, Croatia

jarneric@net.efzg.hr
Maria Čuljak*

Croatian Financial Services

Supervisory Agency

10000 Zagreb, Croatia

culjakmaria1@gmail.com
JEL: G12, G17, C02, C51, C58

Original scientific article

https://doi.org/10.51680/ev.34.1.10

Received: May 19, 2020

Revision received: July 21, 2020

Accepted for publishing: July 31, 2020

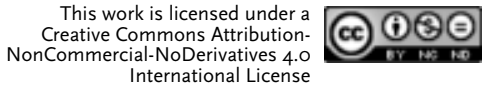

\title{
PREDICTIVE ACCURACY OF OPTION PRICING MODELS CONSIDERING HIGH-FREQUENCY DATA
}

\begin{abstract}
Purpose: Recently, considerable attention has been given to forecasting, not only the mean and the variance, but also the entire probability density function (pdf) of the underlying asset. These forecasts can be obtained as implied moments of future distribution originating from European call and put options. However, the predictive accuracy of option pricing models is not so well established. With this in mind, this research aims to identify the model that predicts the entire pdf most accurately when compared to the ex-post "true" density given by high-frequency data at expiration date.
\end{abstract}

Methodology: The methodological part includes two steps. In the first step, several probability density functions are estimated using different option pricing models, considering the values of major market indices with different maturities. These implied probability density functions are risk neutral. In the second step, the implied pdfs are compared against the "true" density obtained from the high-frequency data to examine which one gives the best fit out-of-sample.

Results: The results support the idea that a "true" density function, although unknown, can be estimated by employing the kernel estimator within high-frequency data and adjusted for risk preferences.

Conclusion: The main conclusion is that the Shimko model outperforms the Mixture Log-Normal model as well as the Edgeworth expansion model in terms of out-of-sample forecasting accuracy. This study contributes to the existing body of research by: i) establishing the benchmark of the "true" density function using high-frequency data, ii) determining the predictive accuracy of the option pricing models and iii) providing applicative results both for market participants and public authorities.

Keywords: Option pricing models, high-frequency data, kernel estimation, benchmark density function, predictive accuracy

* The content of this research does not reflect the official opinion of the Croatian Financial Services Supervisory Agency

\section{Introduction}

The objective of this research is to employ high-frequency data in determining the forecasting power of option pricing models. High-frequency data are used here to provide a reference probability density 
function that would be a benchmark for comparison purpose. The usage of high-frequency data has been driven by technological advances in trading systems, allowing for the recording of almost every transaction that has been realized. The dominance of multilateral trading and electronic trading in regulated markets is growing due to the development of algorithms, the increase in the dynamics of placing orders and liquidity. All the above-mentioned factors provide record-breaking market activity at high frequency, leading to more information of high quality. The academic and practical interest in intraday data, observed at very short intervals of time, are market structures and trading processes that are subject to constant change. The inclusion of electronic trading platforms has automated and accelerated the execution of transactions as well as trading reporting, and has enabled investors to automate their strategies and manage orders in real time. The main purpose of this research is forecasting the future expectation, variance and higher moments of financial assets. In addition to highfrequency data observed every minute, the put and call options data on the stock market indices CAC (Cotation Assistée en Continu), AEX (Amsterdam Exchange index), MIB (Milano Indice di Borsa), and DAX (Deutscher Aktienindex) are considered in this study. The data were obtained from the Thomson Reuters financial service. The research is conducted in two phases. The first phase includes estimating the implied probability density functions at the expiration date using options data. The second phase involves comparing the estimated probability density functions against the reference density function based on high-frequency data, obtained by the kernel estimation method. Employing this estimation method on observed high-frequency data in real time provides an applicative contribution and thus a great advantage over other studies, which mostly rely on simulation data. The used models, i.e. the Shimko model, the Mixture Log-Normal model and the Edgeworth expansion model, are from a class of non-parametric, parametric and semi-parametric option pricing models, respectively. The main objective of the research is to evaluate the predictive accuracy of the mentioned models and to select the most appropriate one that not only best fits the data but also has the highest predictive accuracy. There are some issues regarding the high-frequency data, such as financial market illiquidity, and thus lack of data and uncertainty about sampling frequency selection since time intervals are required to be equidistant and non-overlapping. Comparing the reference probability density function with an estimated risk neutral density function results in recommendations not only for academics, but also practitioners, particularly for financial analysts and market participants, as it provides them with additional information on risk preferences.

\section{Literature review}

It is already documented in the previous studies that current prices of financial instruments reflect information about future expectations and other moments (Bouden, 2007). Option prices give an insight into the expected value of the underlying asset under the assumption of risk neutrality, which makes option prices suitable for estimating the implied probability density function (Čuljak, 2019). Syrdal (2002) presents the first application of risk neutral probability density function on Norwegian option market. Sun (2013) explores application on SP 500 index options, whereas Santos (2011), Bliss and Panigirtzoglou (2002) and Šestanović et al. (2018) study a risk neutral probability density function on European options data. For market participants, the appeal of using the implied probability density function lies in the ability to estimate probabilities in a series of future events, using market perceptions over a period of time. Market analysts and decision makers use this source of information to analyze market sentiment, uncertainty and extreme events, which are commonly embedded in interest rates and exchange rates (Bauwens et al., 2008). It has been shown that a set of call and put option prices with the same maturity, but different strike prices, can be used to extract the entire probability distribution of the underlying asset at the expiration date (Banz \& Miller, 1978; Breeden \& Litzenberger, 1978). Previous studies have used different approaches, i.e. different option pricing models (Bouden, 2007; Liu et al., 2007; Lai, 2014). Despite being the best known and commonly used, the Black and Scholes model assumes that a log-normal distribution is not always applicable in practice. To address this issue, different methods have been proposed to extract risk-neutral density (RND) functions and to examine their robustness and forecasting power (Santos \& Guerra, 2015). Therefore, it is necessary to investigate more closely other models that can be applied in practice. According to Jondeau et al. (2007), alternative option pricing models can be divided into two categories: structural and non-structural. Structural models assume specific price and/or volatility dynamics, while non-structural models allow the estimation of RND without assumptions about the price or 
volatility of the underlying asset (Šestanović et al., 2018). Non-structural models are divided into three categories: parametric, semi-parametric and nonparametric models, which have been considered in this paper also. Parametric models assume the form of a risk-neutral probability density function without prior assumptions about the underlying asset price dynamics (Čuljak, 2019). From the mentioned studies, it can be easily concluded which model is the best fit in-the-sample, but it cannot be generally concluded which model predicts most accurately. An assessment of predictive accuracy requires that the probability density function of the underlying asset is known. Since it is unknown, as are the related moments of the process that generates price dynamics, any attempt of comparison against the assumed data generating process via simulation leaves many doubts and issues. However, as time passes, we can observe what has happened at expiration date by taking high frequencies, i.e. intraday observations at given maturity. This is exactly what this paper deals with.

\section{Implied risk neutral density estimation}

This section presents three option pricing models employed in this paper: the Mixture Log-Normal model (MLN), the Edgeworth expansion model (EE) and the Shimko model (SM). It also provides an overview of option pricing that reduces the limitations of the Black and Scholes model. The Mixture Log-Normal model is a parametric one. According to Bahra (1997), using the combination of two lognormal distributions, the expressions for the European call and put option price are obtained:

$$
\begin{aligned}
& C(X, \tau)=e^{-r \tau} w\left[e^{\alpha_{1}+\frac{1}{2} \beta_{1}^{2}} \Phi\left(d_{1}\right)-X \Phi\left(d_{2}\right)\right]+ \\
& (1-w)\left[e^{\alpha_{1}+\frac{1}{2} \beta_{1}^{2}} \Phi\left(d_{3}\right)-X \Phi\left(d_{4}\right)\right] \\
& P(X, \tau)=e^{-r \tau} w\left[-e^{\alpha_{1}+\frac{1}{2} \beta_{1}^{2}} \Phi\left(-d_{1}\right)-X \Phi\left(-d_{2}\right)\right]+ \\
& (1-w)\left[-e^{\alpha_{1}+\frac{1}{2} \beta_{1}^{2}} \Phi\left(-d_{3}\right)-X \Phi\left(-d_{4}\right)\right]
\end{aligned}
$$

where

$$
\begin{aligned}
& d_{1}=\frac{-\ln (X)+\alpha_{1}+\beta_{1}^{2}}{\beta_{1}} \\
& d_{2}=d_{1}-\beta_{1} \\
& d_{3}=\frac{-\ln (X)+\alpha_{2}+\beta_{2}^{2}}{\beta_{2}} \\
& d_{4}=d_{3}-\beta_{2} .
\end{aligned}
$$

The exercise price is $X, \tau$ is time until expiration, $r$ is a risk-free rate, $w$ is the weight which should be estimated along with parameters $\alpha_{i}, \beta_{i}$ for $i=1,2$, while $\Phi$ is a standard normal cumulative distribution function. It is assumed that the underlying asset price distribution is approximately log-normal, hence a weighted sum of log-normal density functions is used (Santos and Guerra, 2015):

$$
q\left(S_{t}\right)=\sum_{i=1}^{k}\left[w_{i} L\left(\alpha_{i}, \beta_{i}, S_{t}\right)\right]
$$

where $L\left(\alpha_{i}, \beta_{i}, S_{t}\right)$ is the log-normal distribution with parameters $\alpha_{i}$ and $\beta_{i}$, i.e. the location and the scale of each log-normal distribution.

To estimate parameters of the implied risk neutral density function, it is necessary to solve the following minimization problem with respect to the vector $\theta$ that obtains the unknown parameters:

$$
\begin{aligned}
& \min _{\theta} \sum_{i=1}^{n}\left[C_{i}\left(X_{i}, \tau\right)-\tilde{C}_{i}\right]^{2}+\sum_{i=1}^{n}\left[P_{i}\left(X_{i}, \tau\right)-\tilde{P}_{i}\right]^{2}+ \\
& {\left[w e^{\alpha_{1}+\frac{1}{2} \beta_{1}^{2}}+(1-w) e^{\alpha_{1}+\frac{1}{2} \beta_{1}^{2}}-e^{r \tau} S\right]}
\end{aligned}
$$

After the estimation of the parameters $\alpha_{1}, \alpha_{2}, \beta_{1}, \beta_{2}$ and $w$, the same estimates are used in (3) to obtain the implied risk neutral density function on maturity date $T$ (Santos \& Guerra, 2015).

Semi-parametric models suggest an approximation of the true risk-neutral probability density function. The semi-parametric model was used here as the Edgeworth expansion model. According to Jarrow and Rudd (1998) and Jondeau et al. (2007), the call option price expression for Edgeworth expansion is:

$$
\begin{aligned}
& C(Q) \approx C(L)+e^{-r \tau}\left(\gamma_{Q, 1}-\gamma_{L, 1}\right) \frac{K_{L, 2}^{\frac{3}{2}}}{3 !} \frac{d l(X)}{d S_{T}}+ \\
& e^{-r \tau}\left(\gamma_{Q, 2}-\gamma_{L, 2}\right) \frac{K_{L, 2}^{2}}{4 !} \frac{d^{2} l(X)}{d S_{T}^{2}}
\end{aligned}
$$

Using (5) it is easy to calculate implied mean, variance, skewness $\Upsilon_{Q, 1}$ and kurtosis $\Upsilon_{Q, 2}$. Expression for implied risk neutral density function is obtained by differentiating twice (5) with respect to the $X$ and evaluating over $S_{T}$ as follows:

$$
\begin{aligned}
& q\left(S_{T}\right)=l\left(S_{T}\right)-\left(\gamma_{Q, 1}-\gamma_{L, 1}\right) \frac{K_{L, 2}^{\frac{3}{2}}}{6} \frac{d^{2} l(X)}{d S_{T}{ }^{3}}+ \\
& \left(\gamma_{Q, 2}-\gamma_{L, 2}\right) \frac{K_{L, 2}^{2}}{24} \frac{d^{4} l(X)}{d S_{T}^{4}}
\end{aligned}
$$

where partial derivations are iteratively calculated.

Non-parametric models do not assume the form of a risk-neutral probability density function. The last model used in this study is the Shimko model, which is a non-parametric model. The idea is primarily to gather all the information on the volatility curve by 
the polynomial $\sigma(X)$, the exercise price $X$, and then to use the Breeden-Litzenberger expression to estimate the probability density function (Breeden \& Litzenberger, 1978; Jondeau et al., 2007; Shimko, 1993). The following expression for the European call option price is used:

$$
\begin{aligned}
& C(t, S, X, T)=S \Phi\left(d_{1}(\sigma(\mathrm{X}))\right)- \\
& e^{-r \tau} X \Phi\left(d_{2}(\sigma(\mathrm{X}))\right)
\end{aligned}
$$

Finally, the expression for the implied risk neutral density function is obtained:

$q(X)=e^{r \tau} \frac{\partial^{2} C(t, S, \sigma(X), T)}{\partial X^{2}}$

\section{Kernel density estimation using high- frequency data}

High-frequency data have some unique properties, which makes them challenging to deal with for practitioners as well as academics. One of the main features is that high-frequency data are not observed continuously, but rather discretely within not equally distant time points or an interval of time. High-frequency data are mostly nonnegative, positively autocorrelated with significant intraday periodicity and long memory and microstructure noise (Degiannakis \& Floros, 2015; Florescu et al., 2016; Hautsch, 2012). Long memory refers to the decay rate of the statistical dependence of two points with an increase in the time interval, i.e. the linear dependence between two shifted data points decreases very slowly.

Microstructure noise property is a term for a phenomenon observed in high-frequency data that refers to the deviation of the observed price from the base price. The presence of the microstructure noise makes estimates of some parameters biased.
It can be the result of various factors such as bid-ask differences, information asymmetries, price changes discreetness and order latency.

High-frequency data are also characterized by non-normality, i.e. they show the property of fattails. Many option pricing models, such as Black and Scholes, assume normality. However, in practice, it has been shown that unpredictable human behavior leads to extreme events and thus non-normality. Abovementioned features make determining an appropriate distribution complex. However, finding a true but unknown daily distribution based on intraday prices becomes possible using the kernel density estimation method. It should be emphasized that the "true" probability density function can be obtained for each maturity date and then compared with ex-ante density functions derived from several option pricing models. Thus, we compare implied risk-neutral probability density functions and the estimated probability density functions as benchmarks of the "true" densities. Prior to the analysis, the raw data are cleaned as follows. It is assumed that, at each exercise price, call and put options are available in pairs. Cleaning is done by taking a sample that satisfies more criteria than required by the bid price and assuming it is greater than zero. Therefore, there is usually a big difference between the available call and put options prices and the ones actually used. If there are less than ten exercise prices for which we have call and put options, then the probability density function will not be estimated by any of the models used in this paper. The observed stock indices are CAC, AEX, MIB and DAX, i.e. the French, Dutch, Italian and German market index, respectively. Financial instruments used are call and put options on the major indices of the listed financial markets on combinations of options trading dates and options expiration dates in 2018 (Table 1).

Table 1 Options trading dates and expiration dates with respect to four stock market indices

\begin{tabular}{|c|c|c|c|}
\hline Year 2018 & \multicolumn{3}{|c|}{ Options expiration dates } \\
\hline Options trading dates & July 20 & August 17 & September 21 \\
\hline March 23 & & & AEX, DAX, MIB \\
\hline April 20 & & & AEX, CAC \\
\hline May 18 & DAX & & AEX, CAC, DAX, MIB \\
\hline June 22 & AEX, CAC, DAX, MIB & AEX, DAX & AEX, DAX \\
\hline
\end{tabular}

Source: Thomson Reuters 
It can be noticed from Table 1 that options data are not available for all market indices at given trading dates. For example, on trading date May 18, 2018 options data are available for all four indices AEX, CAC, DAX and MIB with expiration on September 21, 2018 (maturity horizon approximately 4 months), but only for DAX index with expiration on July 20, 2018 (maturity horizon one month). Further, we estimate the implied probability density functions on the expiration dates of the Shimko model, Mixture Log-Normal model, and Edgeworth expansion. In addition to options data, highfrequency data were obtained from the Thomas Reuters database for the same expiration dates for which the kernel density method is used to estimate the "true" probability density functions.

\subsection{Kernel estimation of probability density function}

Probability density function $f(x)$ of a random sample $X_{1}, \ldots, X_{\mathrm{R}}$ is usually unknown and should be estimated ex-post. The most well-known assumption free method is the kernel estimation:

$f_{\beta}(x)=(n \beta)^{-1} \sum_{j=1}^{n} K\left(\frac{x-X_{j}}{\beta}\right)$

where the kernel function $\mathrm{K}(\mathrm{x})$ is a symmetric and unimodal probability density function and $\beta$ is the bandwidth. Bandwidth controls the smoothness of the probability density function and affects considerably the graphical presentation of the estimate itself regarding the skewness and kurtosis. The most commonly used kernel functions are: uniform, Epanechnikov and Gaussian. In our research we use a Gaussian kernel function, i.e. $\mathrm{K}(\mathrm{x})=\phi(\mathrm{x})$, where $\phi$ is the standard normal probability density function. The choice of the kernel function has no significant effect on the final density estimation, i.e. studies have shown that the choice of the kernel function does not affect the outcome, while it is more sensitive to the bandwidth (Rosenberg \& Engle, 2002; Arnerić, 2020). The kernel estimator is intuitively very similar to the histogram methodology. Specifically, it primarily estimates the probability density function at each data point, and then sums all these densities to produce a final estimate. Comparing the obtained curve estimate with the histogram (using the same data) would threaten the obvious difference in the histogram smoothness and the kernel estimate as the kernel estimator converges faster to the true probability density function.

\subsection{Bandwidth selection}

Choosing an appropriate kernel bandwidth $\beta$ is crucial in estimating the probability density function $\mathrm{f}(\mathrm{x})$. Many studies recommend some rule of thumbs but also arbitrary selection of $\beta$ (Chiu, 1996). This paper employs kernel bandwidth for each expiration date separately. Although non-parametric kernel estimation is now a standard technique in exploratory data analysis, there is still a great deal of controversy about how to evaluate the validity of an estimate and which kernel bandwidth is optimal. The main point of disagreement is whether to use integrated squared error or mean integrated squared error for selecting the optimal bandwidth. However, in this research the kernel bandwidth parameter is adjusted to obtain the best fit with respect to the high-frequency data for each expiration date under consideration.

\section{Research results}

This section provides the results of comparison between estimated probability density functions, obtained by the three option pricing models, and benchmarks of the "true" probability density functions obtained by kernel estimation using high-frequency data. A graphical and analytical comparison is presented for each maturity date. The study that is most similar to our research compares three parametric density functions obtained by a mixture of two log-normal (MLN), Black-Scholes-Merton (BSM) and generalized beta (GB2) according to Arnerić et al. (2015). Mean square error (MSE) and absolute relative error (ARE) were used for pairwise comparison purpose only, neglecting the "true" probability density function that can be observed ex-post. The Diebold-Mariano test (DM) is used to test which model has a lower MSE (Diebold et al., 1998). The abovementioned parametric models are usually overfitted, creating a wrong impression as to how these models fit the data. Due to unique characteristics of the proposed models, we consider them to be sensitive to different maturity dates. Given that semi-parametric and non-parametric approaches do not explicitly form the risk-neutral probability density function and there is no assumption about the function itself, this paper focuses on Shimko model (SM), Mixture Log-Normal model (MLN) and Edgeworth expansion model (EE). In our paper, we implement out-of-sample comparison methods and determine their predictive accuracy. Two tests were used here, the Die- 
bold-Mariano test and the Kolmogorov-Smirnov test (Pauše, 1993). The results are provided for all combinations of selected trading and expiration dates. For the prices of call and put options the midpoints between bid and ask prices are taken. EURI$\mathrm{BOR}$ is taken as a risk-free interest rate, depending on the forecast horizon. The forecast horizon varies from one month to six months (Table 1). It was assumed that there were no dividend payments. Data processing was done in the "R Studio". The results for the AEX, CAC, DAX and MIB indices are presented graphically from Figure 1 to Figure 18 (see Appendix). The figures present a graphical comparison of implied probability density func- tions using three different option pricing models (MLN, EE, SM) and kernel estimated probability density function based on high-frequency data, i.e. the "true" density (TD). From these figures it can be observed that the kernel density estimation is accurate enough to be used as a benchmark for comparative purpose out-of-sample, and that the Shimko model generally fits the "true" density the best. This result is of great interest for investment industry as it informs analysts which option pricing model to use when assessing the market expectations. Table 2 presents the comparison results obtained by the two-sided Kolmogorov-Smirnov test and the Diebold-Mariano test.

Table 2 Comparison results from the Kolmogorov-Smirnov test and Diebold-Mariano test

\begin{tabular}{|c|c|c|c|c|c|c|}
\hline \multirow{2}{*}{$\begin{array}{l}\text { Index / Expiration date / } \\
\text { Trading date }\end{array}$} & \multicolumn{3}{|c|}{ Kolmogorov-Smirnov test } & \multicolumn{3}{|c|}{ Diebold-Mariano test } \\
\hline & TD-MLN & TD-SM & TD-EE & TD-MLN & TD-SM & TD-EE \\
\hline \multicolumn{7}{|l|}{ AEX } \\
\hline August 17, 2018 & 0.26 & 0.54 & 0.67 & -8.85 & -7.51 & -6.85 \\
\hline June 22, 2018 & $(\mathrm{p}<0.05)$ & $(\mathrm{p}<0.05)$ & $(\mathrm{p}<0.05)$ & $(\mathrm{p}<0.05)$ & $(\mathrm{p}<0.05)$ & $(\mathrm{p}<0.05)$ \\
\hline July 20, 2018 & 0.41 & 0.52 & 0.59 & 2.23 & 0.85 & -2.21 \\
\hline June 22, 2018 & $(\mathrm{p}<0.05)$ & $(\mathrm{p}<0.05)$ & $(\mathrm{p}<0.05)$ & $(\mathrm{p}<0.05)$ & $(\mathrm{p}>0.05)$ & $(\mathrm{p}<0.05)$ \\
\hline September 21, 2018 & 0.38 & 0.61 & 0.72 & -6.75 & -7.81 & -1.32 \\
\hline March 23, 2018 & $(\mathrm{p}<0.05)$ & $(\mathrm{p}<0.05)$ & $(\mathrm{p}<0.05)$ & $(\mathrm{p}<0.05)$ & $(\mathrm{p}<0.05)$ & $(\mathrm{p}<0.05)$ \\
\hline September 21, 2018 & 0.42 & 0.65 & 0.75 & -5.74 & -7.34 & -4.24 \\
\hline April 20, 2108 & $(\mathrm{p}<0.05)$ & $(\mathrm{p}<0.05)$ & $(\mathrm{p}<0.05)$ & $(\mathrm{p}<0.05)$ & $(\mathrm{p}<0.05)$ & $(\mathrm{p}<0.05)$ \\
\hline September 21, 2018 & 0.37 & 0.59 & 0.65 & -7.24 & -8.21 & -6.99 \\
\hline May 18, 2018 & $(\mathrm{p}<0.05)$ & $(\mathrm{p}<0.05)$ & $(\mathrm{p}<0.05)$ & $(\mathrm{p}<0.05)$ & $(\mathrm{p}<0.05)$ & $(\mathrm{p}<0.05)$ \\
\hline September 21, 2018 & 0.36 & 0.51 & 0.6 & -5.41 & -7.96 & -7.38 \\
\hline June 22, 2018 & $(\mathrm{p}<0.05)$ & $(\mathrm{p}<0.05)$ & $(\mathrm{p}<0.05)$ & $(\mathrm{p}<0.05)$ & $(\mathrm{p}<0.05)$ & $(\mathrm{p}<0.05)$ \\
\hline \multicolumn{7}{|l|}{$\mathrm{CAC}$} \\
\hline July 20, 2018 & 0.53 & 0.80 & 0.38 & -4.06 & -7.55 & -0.87 \\
\hline June 22, 2018 & $(\mathrm{p}<0.05)$ & $(\mathrm{p}<0.05)$ & $(\mathrm{p}<0.05)$ & $(\mathrm{p}<0.05)$ & $(\mathrm{p}<0.05)$ & $(\mathrm{p}<0.05)$ \\
\hline September 21, 2018 & 0.54 & 0.47 & 0.54 & -7.04 & -8.62 & -5.41 \\
\hline April 20, 2018 & $(\mathrm{p}<0.05)$ & $(\mathrm{p}<0.05)$ & $(\mathrm{p}<0.05)$ & $(\mathrm{p}<0.05)$ & $(\mathrm{p}<0.05)$ & $(\mathrm{p}<0.05)$ \\
\hline September 21, 2018 & 0.31 & 0.35 & 0.53 & -7.99 & -9.82 & -8.58 \\
\hline May 18, 2018 & $(\mathrm{p}<0.05)$ & $(\mathrm{p}<0.05)$ & $(\mathrm{p}<0.05)$ & $(\mathrm{p}<0.05)$ & $(\mathrm{p}<0.05)$ & $(\mathrm{p}<0.05)$ \\
\hline August 17, 2018 & 0.35 & 0.47 & 0.53 & -18.06 & -10.94 & -7.00 \\
\hline June 22, 2018 & $(\mathrm{p}<0.05)$ & $(\mathrm{p}<0.05)$ & $(\mathrm{p}<0.05)$ & $(\mathrm{p}<0.05)$ & $(\mathrm{p}<0.05)$ & $(\mathrm{p}<0.05)$ \\
\hline
\end{tabular}




\begin{tabular}{|c|c|c|c|c|c|c|}
\hline \multirow{2}{*}{$\begin{array}{l}\text { Index / Expiration date / } \\
\text { Trading date }\end{array}$} & \multicolumn{3}{|c|}{ Kolmogorov-Smirnov test } & \multicolumn{3}{|c|}{ Diebold-Mariano test } \\
\hline & TD-MLN & TD-SM & TD-EE & TD-MLN & TD-SM & TD-EE \\
\hline \multicolumn{7}{|l|}{ DAX } \\
\hline July 20, 2018 & 0.37 & 0.55 & 0.38 & -5.85 & -1.45 & -5.68 \\
\hline May 18, 2018 & $(\mathrm{p}<0.05)$ & $(\mathrm{p}<0.05)$ & $(\mathrm{p}<0.05)$ & $(\mathrm{p}<0.05)$ & $(\mathrm{p}>0.05)$ & $(\mathrm{p}<0.05)$ \\
\hline July 20, 2018 & 0.31 & 0.46 & 0.49 & 1.94 & 1.34 & -0.76 \\
\hline June 22, 2018 & $(\mathrm{p}<0.05)$ & $(\mathrm{p}<0.05)$ & $(\mathrm{p}<0.05)$ & $(\mathrm{p}>0.05)$ & $(\mathrm{p}>0.05)$ & $(\mathrm{p}<0.05)$ \\
\hline September 21, 2018 & 0.34 & 0.15 & 0.13 & 0.34 & -5.18 & -7.70 \\
\hline March 23, 2018 & $(\mathrm{p}<0.05)$ & $(\mathrm{p}<0.05)$ & $(\mathrm{p}>0.05)$ & $(\mathrm{p}>0.05)$ & $(\mathrm{p}<0.05)$ & $(\mathrm{p}<0.05)$ \\
\hline September 21, 2018 & 0.30 & 0.31 & 0.35 & 6.45 & 3.10 & -2.64 \\
\hline May 18, 2018 & $(\mathrm{p}<0.05)$ & $(\mathrm{p}<0.05)$ & $(\mathrm{p}<0.05)$ & $(\mathrm{p}<0.05)$ & $(\mathrm{p}<0.05)$ & $(\mathrm{p}<0.05)$ \\
\hline September 21, 2018 & 0.36 & 0.35 & 0.43 & -4.35 & -3.02 & -2.64 \\
\hline June 22, 2018 & $(\mathrm{p}<0.05)$ & $(\mathrm{p}<0.05)$ & $(\mathrm{p}<0.05)$ & $(\mathrm{p}<0.05)$ & $(\mathrm{p}<0.05)$ & $(\mathrm{p}<0.05)$ \\
\hline \multicolumn{7}{|l|}{ MIB } \\
\hline July 20, 2018 & 0.22 & 0.31 & 0.29 & 1.35 & -9.73 & -6.34 \\
\hline June 22, 2018 & $(\mathrm{p}<0.05)$ & $(\mathrm{p}<0.05)$ & $(\mathrm{p}<0.05)$ & $(p>0.05)$ & $(\mathrm{p}<0.05)$ & $(\mathrm{p}<0.05)$ \\
\hline September 21, 2018 & 0.34 & 0.27 & 0.20 & -2.50 & -6.54 & -6.91 \\
\hline March 23, 2018 & $(\mathrm{p}<0.05)$ & $(\mathrm{p}<0.05)$ & $(\mathrm{p}<0.05)$ & $(\mathrm{p}<0.05)$ & $(\mathrm{p}<0.05)$ & $(\mathrm{p}<0.05)$ \\
\hline September 21, 2018 & 0.38 & 0.35 & 0.28 & -6.56 & -7.84 & -3.65 \\
\hline May 18, 2018 & $(\mathrm{p}<0.05)$ & $(\mathrm{p}<0.05)$ & $(\mathrm{p}<0.05)$ & $(\mathrm{p}<0.05)$ & $(\mathrm{p}<0.05)$ & $(\mathrm{p}<0.05)$ \\
\hline
\end{tabular}

Source: Authors' calculation using R Studio and Thomson Reuters data

In most of the cases, we reject the null hypothesis of the Kolmogorov-Smirnov test proposing that the estimated probability densities originate from the "true" density function. The null hypothesis is rejected at a significance level of $5 \%$ in most cases except from DAX index on trading date of March 23, 2018 and maturity date of September 21, 2018. In that case we did not reject the null hypothesis of KS test at a significance level of $5 \%(p>0.05)$. This means that the probability density function implied by the Shimko model and the "true" density function obtained by the Kernel estimator are the same.

Table 2 also provides aggregate DM test results for all observed stock indices and combinations of maturity and trading dates. DM is used to test the null hypothesis for the observed pricing models having the same forecasting ability. In the example of AEX stock index on maturity date August 17, 2018 and trading date June 22, 2018, the null hypothesis at a significance level of $5 \%$ was rejected. In an equal number of cases, the Mixture Log-Normal model, the Shimko model, and the Edgeworth expansion model have been shown to have the same prognostic accuracy i.e. we did not reject the null hypothesis at a significance level of $5 \%$. It is important to emphasize that in the case of DAX market index on the trading date of June 22, 2018 and expiration date July 20, 2018 all the models had the same prognostic accuracy.

\section{Conclusion}

Probability density function can be estimated using high-frequency data by employing Kernel estimator. Estimated probability density is sufficiently close to the "true" density and thus can be used as a benchmark or a reference function in determining the predictive accuracy of three option pricing models considered. Finding a benchmark for comparison purpose out-of-sample is the main contribution of this research, i.e. for each expiration date 
and every stock market index, appropriate benchmark was found with respect to Kernel bandwidth.

From the perspective that Kernel estimator provides referential probability density function, it can be concluded that Shimko model is the best fitting model out-of-sample when compared against the "true" density. Moreover, the null hypothesis of the Kolmogorov-Smirnov test was rejected in most cases for all market indices and all combinations of trading and expiration dates. The results of the Diebold-Mariano test did not reject the null hypothesis implying that the models have the same predictive accuracy. According to the graphical presentations and the Kolmogorov-Smirnov test, we can conclude that the Shimko model predicts most accurately. Comparing a benchmark density function with an estimated risk-neutral density function has shown solid results that provide recommendations for application in academic research as well as in the financial industry. These results can be very helpful for further research into volatility estimation using high-frequency data. Concerning the application of the expected results, it will be possible to observe certain characteristics within the development of predictive methods and their optimization. The paper provides analysts and investors in fintech areas with recommendations with regard to forecasting methodology and the reference financial series for monitoring future developments on the capital markets.

\section{Acknowledgement}

This work has been supported by Croatian Science Foundation under the project "Volatility measurement, modelling and forecasting" (5199) along with ZP UNIRI project "Financial and Social Aspects of Developments and Liberalization in EU Energy Markets" (3/18).

This research has received funding from the European Union's Horizon 2020 research and innovation program FIN-TECH: A Financial supervision and Technology compliance training programme under the grant agreement No 825215 (Topic: ICT35-2018, Type of action: CSA). 


\section{REFERENCES}

1. Arnerić, J., Aljinović, Z. \& Poklepović, T. (2015). Extraction of market expectations from risk-neutral density. Proceedings of Rijeka Faculty of Economics: Journal of Economics and Business, 33(2), 235-256. https://doi.org/10.18045/zbefri.2015.2.235

2. Arnerić, J. (2020). Realized density estimation using intraday prices. Croatian Review of Economics, Business and Social Statistics, 6(1), 1-9. https://doi.org/10.2478/crebss-2020-0001

3. Bahra, B. (1997). Implied risk-neutral probability density functions from option prices: Theory and application (Bank of England Working Paper No. 66). London: Bank of England.

4. Banz, R. W. \& Miller, M. H. (1978). Prices for state-contingent claims: Some estimates and applications. The Journal of Business, 51(4), 653-672. https://doi.org/10.1086/296026

5. Bauwens, L., Pohlmeier, W. \& Veredas, D. (2008). High-Frequency Financial Econometrics: Recent Developments. Physica-Verlag. https://doi.org/10.1007/978-3-7908-1992-2

6. Bliss, R. R. \& Panigirtzoglou, N. (2002). Testing the stability of implied probability density functions. Journal of Banking and Finance, 26(2-3), 381-422. https://doi.org/10.1016/S0378-4266(01)00227-8

7. Bouden, A. (2007). Comparing risk neutral density estimation methods using simulated option data. In Ao, S. I. et al. (Eds.). Proceedings of the World Congress on Engineering WCE 2007 (pp. 1029-1037). London: Newswood Limited.

8. Breeden, D. T. \& Litzenberger, R. H. (1978). Prices of state-contingent claims implicit in option prices. The Journal of Business, 51(4), 621-651. https://doi.org/10.1086/296025

9. Chiu, S. T. (1996). A comparative review of bandwidth selection for kernel density estimation. Statistica Sinica, 6(1), 129-145.

10. Čuljak, M. (2019). Analiza prediktivne sposobnosti opcijskih modela vrednovanja visokofrekventnim podacima [Postgraduate thesis, University of Zagreb]. University of Zagreb, Faculty of Economics and Business.

11. Degiannakis, S. \& Floros, C. (2015). Modelling and Forecasting High-Frequency Financial Data. Palgrave Macmillan. https://doi.org/10.1057/9781137396495

12. Diebold, F. X., Gunther, T. A. \& Tay, A. S. (1998). Evaluating density forecasts with applications to financial risk management. International Economic Review, 39(4), 863-883. https://doi.org/10.2307/2527342

13. Florescu, I., Mariani, M. C., Stanley, H. E. \& Viens, F. G. (2016). Handbook of High-Frequency and Modelling in Finance. John Wiley and Sons. https://doi.org/10.1002/9781118593486

14. Hautsch, N (2012). Econometrics of Financial High-Frequency Data. Springer-Verlag. https://doi.org/10.1007/978-3-642-21925-2

15. Jarrow, R. \& Rudd, A. (1982). Approximate option valuation for arbitrary stochastic processes. Journal of Financial Economics, 10(3), 347-369. https://doi.org/10.1016/0304-405X(82)90007-1

16. Jondeau, E., Poon, S. H. \& Rockinger, M. (2007). Financial Modelling Under Non-Gaussian Distributions. Springer-Verlag.

17. Lai, W. N. (2014). Comparison of methods to estimate option implied risk-neutral densities. Quantitative Finance, 14(10), 1839-1855. https://doi.org/10.1080/14697688.2011.606823

18. Liu, X., Shackleton, M. B., Taylor, S. J. \& Xu, X. (2007). Closed-form transformations from risk-neutral to real-world distributions. Journal of Banking and Finance, 31(5), 1501-1520.

https://doi.org/10.1016/j.jbankfin.2006.09.005

19. Pauše, Ž. (1993). Uvod u matematičku statistiku. Školska knjiga.

20. Rosenberg, J. V. \& Engle, R. F. (2002). Empirical pricing kernels. Journal of Financial Economics, 64(3), 341-372. https://doi.org/10.1016/S0304-405X(02)00128-9

21. Santos, A. D. (2011). Implied probability density functions: Estimation using hypergeometric, spline and lognormal functions [Master's thesis, University of Lisbon]. University of Lisbon, Department of Finance. 
22. Santos, A. D. \& Guerra, J. (2015). Implied risk neutral densities from option prices: Hypergeometric, spline, lognormal, and Edgeworth functions. Journal of Futures Markets, 35(7), 655-678. https://doi.org/10.1002/fut.21668

23. Shimko, D. (1993). Bounds of probability. Risk, 6(4), 33-37.

24. Sun, P. (2013). Risk neutral and real world densities for the SP 500 index during the crisis period from 2008 to 2009 [Doctoral dissertation, Lancaster University]. Lancaster University, Management School.

25. Syrdal, S. A. (2002). A study of Implied Risk-Neutral Density Functions in the Norwegian Option Market (Norges Bank Working Paper No. 13). Oslo: Norges Bank.

26. Šestanović, T., Arnerić, J. \& Aljinović, Z. (2018). Non-structural approach to implied moments extraction. Economic Research, 31(11), 1923-1939. https://doi.org/10.1080/1331677X.2018.1530607 


\section{Appendix}

Figure 1 Comparison of risk-neutral densities obtained on June 22, 2018 for AEX index against the true density of AEX index with a maturity date of August 17, 2018

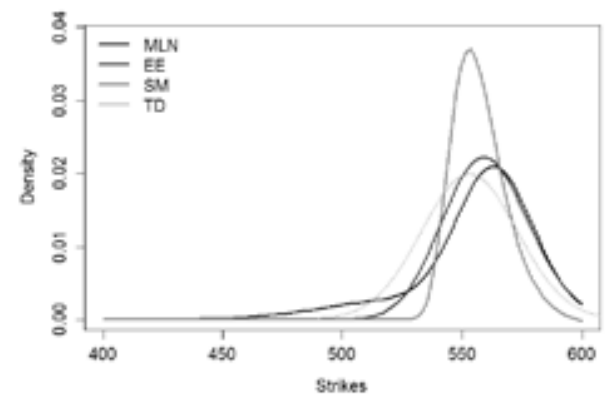

Source: Authors' calculation using R Studio and Thomson Reuters data

Figure 2 Comparison of risk-neutral densities obtained on June 22, 2018 for AEX index against the true density of AEX index with a maturity date of July 20, 2018

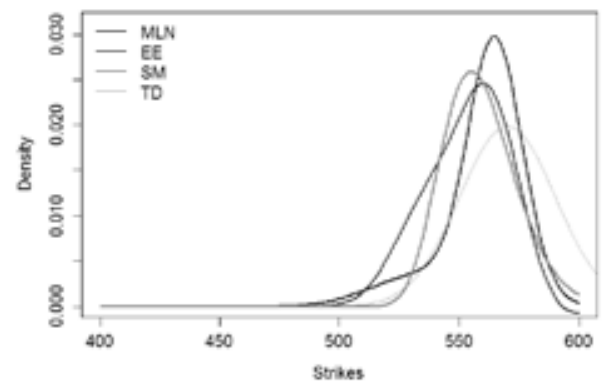

Source: Authors' calculation using R Studio and Thomson Reuters data
Figure 3 Comparison of risk-neutral densities obtained on March 23, 2018 for AEX index against the true density of AEX index with a maturity date of September 21, 2018

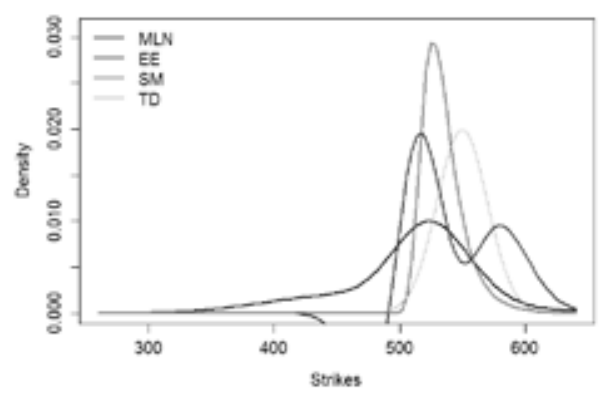

Source: Authors' calculation using R Studio and Thomson Reuters data

Figure 4 Comparison of risk-neutral densities obtained on April 20, 2018 for AEX index against the true density of AEX index with a maturity date of September 21, 2018

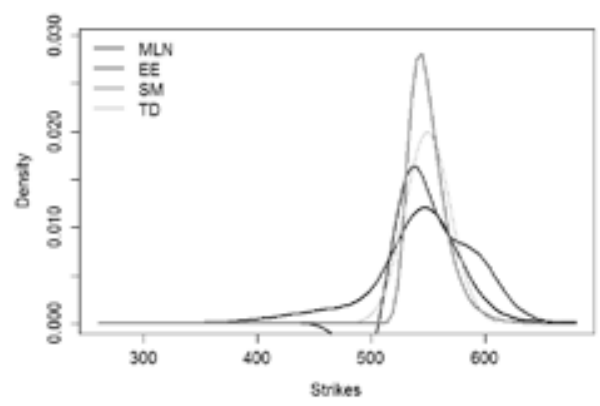

Source: Authors' calculation using R Studio and Thomson Reuters data 
Figure 5 Comparison of risk-neutral densities obtained on May 18, 2018 for AEX index against the true density of AEX index with a maturity date of September 21, 2018

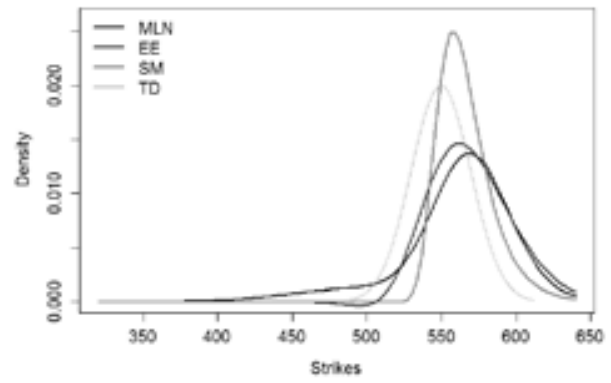

Source: Authors' calculation using R Studio and Thomson Reuters data

Figure 6 Comparison of risk-neutral densities obtained on June 22, 2018 for AEX index against the true density of AEX index with a maturity date of September 21, 2018

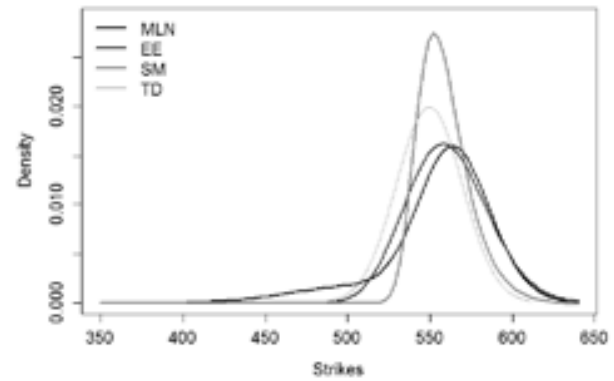

Source: Authors' calculation using R Studio and Thomson Reuters data

Figure 7 Comparison of risk-neutral densities obtained on June 22, 2018 for CAC index against the true density of CAC index with a maturity date of July 20, 2018

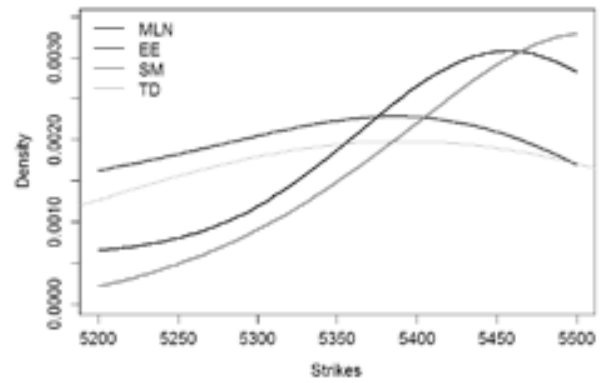

Source: Authors' calculation using R Studio and Thomson Reuters data
Figure 8 Comparison of risk-neutral densities obtained on April 20, 2018 for CAC index against the true density of CAC index with a maturity date of September 21, 2018

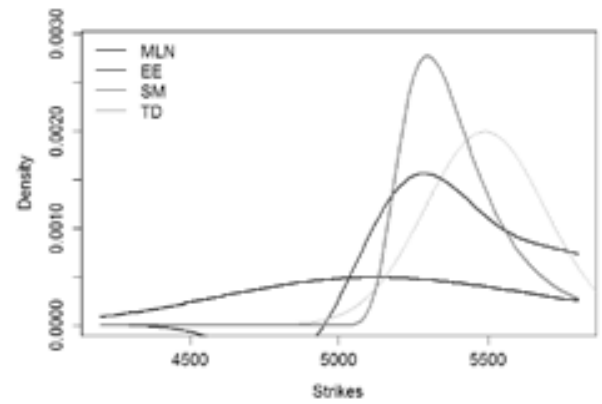

Source: Authors' calculation using R Studio and Thomson Reuters data

Figure 9 Comparison of risk-neutral densities obtained on May 18, 2018 for CAC index against the true density of CAC index with a maturity date of September 21, 2018

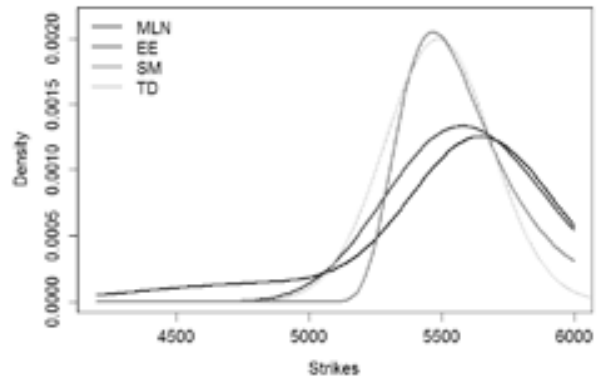

Source: Authors' calculation using R Studio and Thomson Reuters data

Figure 10 Comparison of risk-neutral densities obtained on June 22, 2018 for DAX index against the true density of DAX index with a maturity date of August 17, 2018

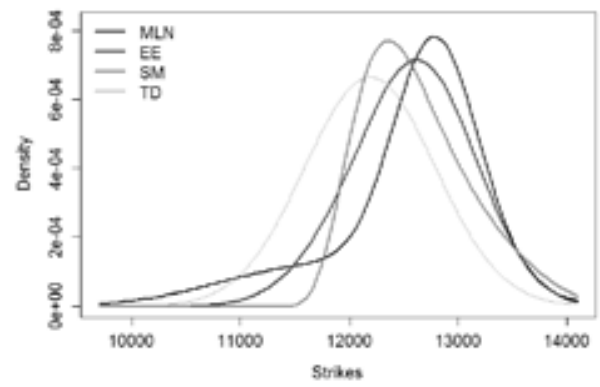

Source: Authors' calculation using R Studio and Thomson Reuters data 
Figure 11 Comparison of risk-neutral densities obtained on May 18, 2018 for DAX index against the true density of $D A X$ index with a maturity date of July 20, 2018

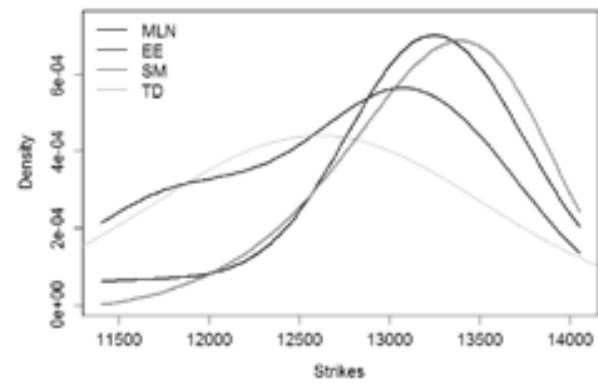

Source: Authors' calculation using R Studio and Thomson Reuters data

Figure 12 Comparison of risk-neutral densities obtained on June 22, 2018 for DAX index against the true density of $D A X$ index with a maturity date of July 20, 2018

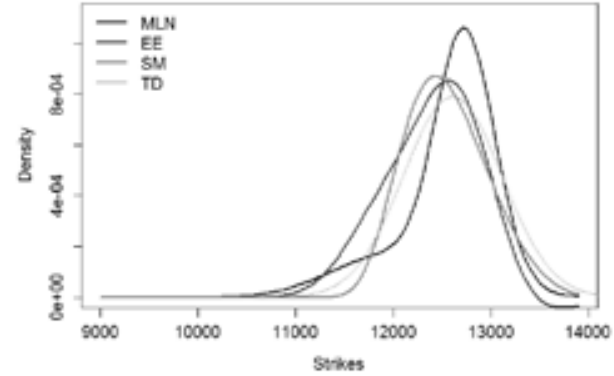

Source: Authors' calculation using R Studio and Thomson Reuters data

Figure 13 Comparison of risk-neutral densities obtained on March 23, 2018 for DAX index against the true density of $D A X$ index with a maturity date of September 21, 2018

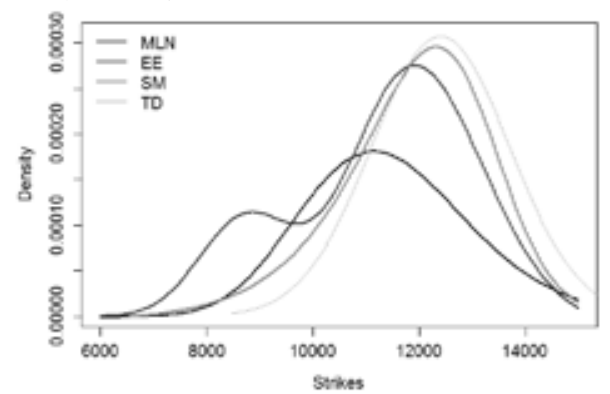

Source: Authors' calculation using R Studio and Thomson Reuters data
Figure 14 Comparison of risk-neutral densities obtained on May 18, 2018 for DAX index against the true density of $D A X$ index with a maturity date of September 21, 2018

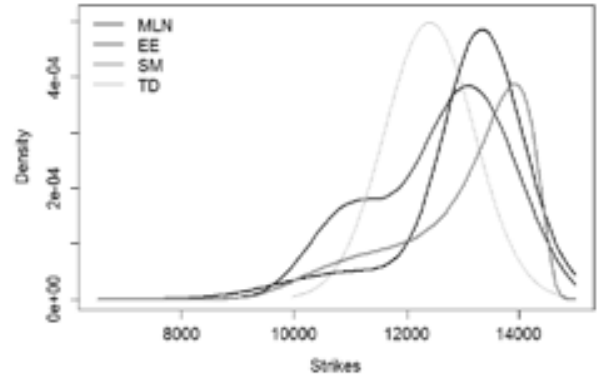

Source: Authors' calculation using R Studio and Thomson Reuters data

Figure 15 Comparison of risk-neutral densities obtained on June 22, 2018 for DAX index against the true density of $D A X$ index with a maturity date of September 21, 2018

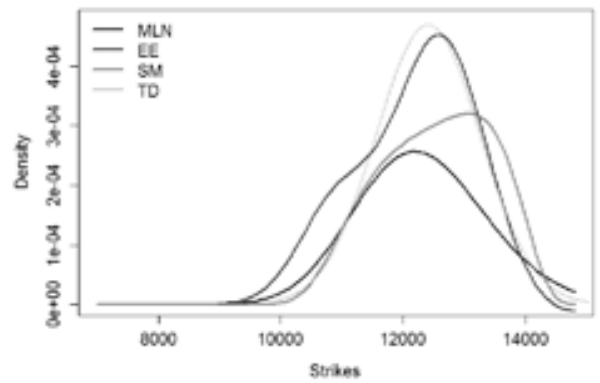

Source: Authors' calculation using R Studio and Thomson Reuters data

Figure 16 Comparison of risk-neutral densities obtained on June 22, 2018 for MIB index against the true density of MIB index with a maturity date of July 20, 2018

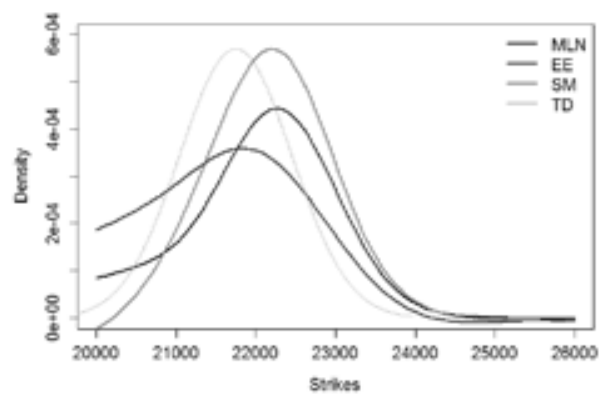

Source: Authors' calculation using R Studio and Thomson Reuters data 
Figure 17 Comparison of risk-neutral densities obtained on March 23, 2018 for MIB index against the true density of MIB index with a maturity date of September 21, 2018

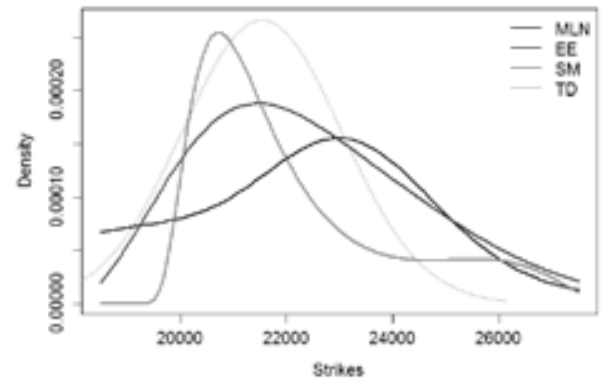

Source: Authors' calculation using R Studio and Thomson Reuters data
Figure 18 Comparison of risk-neutral densities obtained on May 18, 2018 for MIB index against the true density of MIB index with a maturity date of September 21, 2018

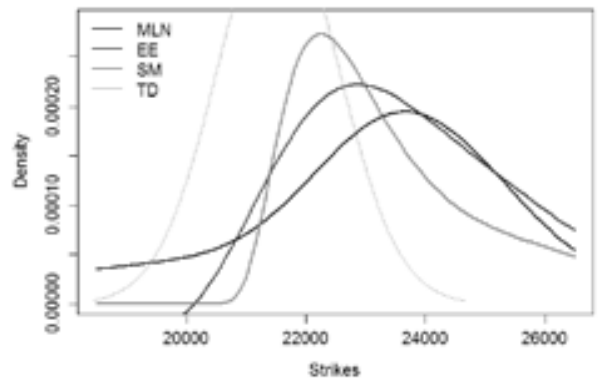

Source: Authors' calculation using R Studio and Thomson Reuters data 